\title{
A Study on Ocular Manifestations Seen in Patients with Cerebral Palsy
}

\author{
Reshma Shaikh $^{1 *}$ \\ ${ }^{1}$ Consultant Ophthalmologist, Associate Professor, Navodaya Medical College Hospital and Research Centre, \\ Raichur, India
}

*Corresponding Author: Reshma Shaikh, Consultant Ophthalmologist, Associate Professor, Navodaya Medical College Hospital and Research Centre, Raichur, India; Email: drreshma_ophtho@yahoo.co.in

Received Date: 24-11-2020; Accepted Date: 16-12-2020; Published Date: 25-12-2020

Copyright $^{\oplus} 2020$ by Shaikh R. All rights reserved. This is an open access article distributed under the terms of the Creative Commons Attribution License, which permits unrestricted use, distribution, and reproduction in any medium, provided the original author and source are credited.

\begin{abstract}
Background: Cerebral palsy is a multitude of neurological disorders due to abnormal development of brain or permanent insult to the brain tissue affecting the muscle tone, movement of limbs thus leading to motor abnormalities. It hinders the body's ability to move in a coordinated and purposeful way.

Aim: To evaluate and assess the manifestations in the eyes of patients with cerebral palsy including visual acuity, refractive error, ocular alignment and movement, anterior and posterior segment of the eye.

Methodology: This study included 100 eyes of 50 patients who were diagnosed with cerebral palsy by paediatrician between January-June 2020 .

Results: In this study we found that spastic type of cerebral palsy was the most common. 84\% of children were found to have refractive error. Hypermetropia (36\%) followed by hypermetropic astigmatism (30\%) was most commonly seen refractive error among these children. Alternating convergent squint (20\%) was the most common form of strabismus. Ptosis (2\%), nystagmus (8\%) and optic nerve head hypoplasia (6\%) were also found. Cortical visual impairment was found in $12 \%$ of children with cerebral palsy. Healthcare professionals need to be aware of these manifestations and the parents/guardians need to be counselled regarding the upbringing of such children so as to influence overall development of children with cerebral palsy.
\end{abstract}


Conclusion: Most of the children with cerebral palsy are found to have some ocular abnormalities. Hence a regular ophthalmic examination has to be conducted at regular intervals of time to prevent complications in these children. This will help to cater to the needs of these children ensuring their overall development.

\section{Keywords}

Refractive Error; Squint; Ocular Abnormalities; Brain Tissue

\section{Introduction}

Cerebral palsy is a neurological disorder that is stationary, chronic, permanent and affects the movement and posture of the body. It is one of the most common motor disability seen in childhood [1]. The symptoms of cerebral palsy may vary from person to person from being mild to severe. Along with motor disorders cerebral palsy may involve disturbances of cognition, communication, intellectual impairment abnormalities of sensation, perception, hearing and behaviour. It may be associated with a seizure disorder. Cerebral palsy can be classified as spastic, ataxic, athetoid, or atonic type [1]. Ocular manifestations seen in cerebral palsy include a wide range of refractive errors, nystagmus, strabismus, cortical visual impairment as well as optic disc changes.

\section{Aim of Study}

1. To evaluate manifestations in eyes of patients with cerebral palsy

2. To assess vision and refractive errors seen in patients with cerebral palsy

3. To assess abnormalities in anterior and posterior segment of eyes of cerebral palsy patients

\section{Methods}

This is a hospital based, descriptive, cross-sectional, non-interventional study done in Navodaya Medical College Hospital and Research Centre. Duration of this study was from august 2019 to August 2020. Study involved 50 diagnosed cases of cerebral palsy who were referred by paediatrician to Department of Ophthalmology. Each and every child with cerebral palsy was included in this study only after obtaining a well-informed consent either from the parent or guardian.

In this study we included patients with motor disability which was confirmed by a paediatrician as a case of cerebral palsy. Age group considered included children between 6 months- 18 years of age. 
A complete and detailed history regarding medical and ocular condition was elicited from all patients attenders. It also included history regarding birth, antenatal, natal, postnatal, attainment of milestones, immunization and family history.

Examination was conducted by placing the child either on the parent's lap or a wheelchair. Visual acuity (with and without aids) was checked for one eye at a time. Different methods were used to evaluate the visual acuity based on the age and co-operation of the patient. These tests included Snellen chart, Kay picture test, central steady maintained method and Preferential Looking Chart.

Central Steady Maintained (CSM) method was performed in those children where testing of visual acuity was difficult by other methods. CSM was performed by covering one eye of the child and making the child fixate on light with the other eye. The uncovered eye was checked for corneal reflex, fixation of eyes on moving light and maintenance of fixation when the previously covered eye is uncovered. Grading was done accordingly.

Cycloplegic refraction was done in some cases using homatropine (2\%) eye drops followed by retinoscopy after 90 mins.

Refractive error was divided as follows: myopia $\geq 0.50 \mathrm{D}$; hyperopia as $\geq+1.00 \mathrm{D}$; astigmatism as $\geq-1.00 \mathrm{D}$ along any meridian; and anisometropia (mean sphere) as $\geq 1.00 \mathrm{D}$ between the corresponding meridians of both eyes.

Ocular motility in six different cardinal gazes was assessed by moving bright colourful object or torchlight. The Doll's Head Tilt test was done in patients who were uncooperative. Strabismus was confirmed by performing Hirschberg test and cover uncover test. Wherever possible nystagmus was assessed.

Hand held slit lamp or a standard slit lamp biomicroscope was used and a detailed examination of the anterior segment was done. In cases where examination was impossible as the child was uncooperative, sedation was attained using midazolam $0.1 \mathrm{mg} / \mathrm{kg} / \mathrm{dose}$. The assessment of posterior segment was done using direct ophthalmoscope or indirect ophthalmoscope after full dilatation of pupil was attained. If decreased visual acuity was found despite normal ocular findings, it raised a suspicion of cortical visual impairment. Evaluation of the collected data was done and the results were subjected to analysis accordingly.

Assessment of ocular alignment using Hirschberg test was done by shining light from a torch into the child's eye and the reflection of the light in the cornea was looked for. Based on the distance of the corneal light reflection from the pupillary centre grading was done. Cover uncover test was also used to assess ocular alignment in some cases. In this test alternate

Shaikh R | Volume 1; Issue 1 (2020) | JOAR-1(1)-005 | Research Article

Citation: Shaikh R. A Study on Ocular Manifestations Seen in Patients with Cerebral Palsy. J

Ophthalmol Adv Res. 2020;1(1):1-7.

DOI: http://dx.doi.org/10.46889/JOAR.2020.1105 
covering of normal and deviating eye is done and any movement of eye is checked. Absence of any movement indicates orthophoria.

\section{Results}

In our study of 50 cerebral palsy patients, $70 \%$ of the children were less than 7 years of age and $30 \%$ were above 7 years and below 18 years of age. Equal number of either gender was included making Male: Female ratio 1:1. Based on the type of cerebral palsy we found that $66 \%$ have spastic type of cerebral palsy, $24 \%$ had hypotonic type and $10 \%$ had mixed type of cerebral palsy (Table 1 and 2).

\begin{tabular}{|c|c|c|}
\hline Age & Number & Percentage \\
\hline 6 months- 7 years & 35 & $70 \%$ \\
\hline >7 years & 15 & $30 \%$ \\
\hline
\end{tabular}

Table 1: Age distribution and percentage.

\begin{tabular}{|c|c|c|}
\hline Types of Cerebral Palsy & Frequency & Percentage \\
\hline Spastic & 33 & $66 \%$ \\
\hline Hypotonic & 12 & $24 \%$ \\
\hline Mixed & 5 & $10 \%$ \\
\hline
\end{tabular}

Table 2: Types of cerebral palsy.

Visual acuity was checked using age appropriate methods. Kay Picture test was used in 14\% whereas Central Steady and Maintained was done in $42 \%$, Sheridan Gardiner in $18 \%$ and Preferential looking test in $20 \%$. Visual acuity could not be assessed in 3 children (Table 3 ).

\begin{tabular}{|c|c|}
\hline Test Used & Percentage of Children \\
\hline Kay Picture Test & $14 \%$ \\
\hline Central Steady and Maintained & $42 \%$ \\
\hline Sheridan Gardiner & $18 \%$ \\
\hline Preferential Looking Test & $20 \%$ \\
\hline
\end{tabular}

Table 3: Different Methods for assessing visual acuity in children with cerebral palsy.

Hypermetropia (36\%) was the most prevalent refractive error found in both the eyes. It was followed by hypermetropic astigmatism, myopic astigmatism and myopia in the right eye. Whereas, hypermetropic astigmatism, myopic astigmatism and myopia in decreasing order in the left eye (Table 4 and 5). 


\begin{tabular}{|c|c|c|}
\hline Refractive error & Count & Percentage \\
\hline Emmetropia & 6 & $12 \%$ \\
\hline Hypermetropia & 19 & $38 \%$ \\
\hline Hypermetropic astigmatism & 13 & $26 \%$ \\
\hline Myopia & 5 & $10 \%$ \\
\hline Myopic astigmatism & 7 & $14 \%$ \\
\hline
\end{tabular}

Table 4: Refractive error in right eye.

\begin{tabular}{|c|c|c|}
\hline Refractive Error & Count & Percentage \\
\hline Emmetropia & 10 & $20 \%$ \\
\hline Hypermetropia & 17 & $34 \%$ \\
\hline Hypermetropic astigmatism & 14 & $28 \%$ \\
\hline Myopia & 3 & $6 \%$ \\
\hline Myopic astigmatism & 6 & $12 \%$ \\
\hline
\end{tabular}

Table 5: Refractive error in the left eye.

\section{Ocular Alignment}

On assessing ocular alignment, 20\% (10) children were found to have orthophorically aligned eyes. $20 \%$ (10) were found to have alternating convergent squint, 16\% (8) were found to have esotropia and $8 \%$ (4) were found to have exotropia (Table 6).

\begin{tabular}{|c|c|c|}
\hline Ocular Alignment & Count & Percentage \\
\hline Alternating Convergent Squint & 10 & $20 \%$ \\
\hline Esotropia & 8 & $16 \%$ \\
\hline Exotropia & 4 & $8 \%$ \\
\hline Normal & 23 & $46 \%$ \\
\hline
\end{tabular}

Table 6: Ocular alignment found in the eye.

\section{Extraocular Motility}

Extraocular motility was assessed in 90\% (45) children. Among them, 97.7\% (44) had ocular movements in all positions of gazes. Only one patient was found with restriction of extraocular movement that being limitation of abduction unilaterally (Table 7).

On examining the anterior segment, bilateral ptosis was found in 1 child (2\%).

Posterior segment examination revealed optic atrophy in 20 eyes (20\%) and optic nerve head hypoplasia in 6 eyes (6\%). Nystagmus was seen in 4 patients $(8 \%)$. Cortical visual impairment was found in 6 patients $(12 \%)$. 


\begin{tabular}{|c|c|c|}
\hline Posterior Segment Findings & Count & Percentage \\
\hline Optic Atrophy & 20 & $20 \%$ \\
\hline Optic Nerve Head Hypoplasia & 6 & $6 \%$ \\
\hline
\end{tabular}

Table 7: Posterior segment findings.

\section{Discussion}

In our study of 50 patients with Cerebral Palsy, Male: Female ratio is 1:1 which is different when compared to the study by Katoch $S$, et al., [2]. The age group in our study varied from 6 months to eighteen years, out of which $70 \%$ of the patients were less 7 years of age. Spastic (66\%) type of $\mathrm{CP}$ is the most common followed by hypotonic (24\%) and mixed (10\%) and it is in accordance with the study done by Olubunmi, et al. [3].

Refractive error was the most common abnormality found in our study and it accounted for $84 \%$ of all eyes under study. Govinda, et al., in his study found strabismus (35.7\%) to be the most frequent abnormality [4]. Among the refractive errors, hypermetropia (36\%) had a higher incidence rate followed by hypermetropic astigmatism (30\%) and myopic astigmatism (13\%). In a study performed by Sabita Katoch, et al., astigmatism (34\%) as the most common refractive error, succeeded by hypermetropia (20\%) and myopia (13.5\%) [2]. Many factors may contribute to this few being inability of the children to understand the procedure, inattention, fatiguability, uncooperation while performing tests. It's an uphill task to assess the visual acuity and best corrected visual acuity in cerebral palsy children. By using glasses best corrected visual acuity of $6 / 6$ was attained in 5 eyes and they were given spectacle correction. Visual acuity in only about two thirds of the patients was assessed using test like Snellen chart, Sheridan Gardiner Chart, Kay Picture Chart, and Preferential Looking Chart. CSM method was used in the rest which is not that reliable. In uncooperative and non-verbal children visual function assessment could be done with visual evoked potential. It is a better alternative but could not be performed in our set up due to non-availability.

The prevalence of strabismus was found to be $44 \%$. Even a study done by Sanjay Marasini, et al., showed quite a similar result of 36\% [5]. Alternating convergent squint which accounted for $20 \%$ was the most common type. Esotropia (16\%) and exotropia (8\%) were also noted. Nystagmus was seen in $8 \%$ of the patients. A study done by Amita Govind. et al., showed an incidence was $10 \%$ which was similar to our study [6].

All the eyes had normal ocular motility except in 1 eye where abduction was limited. But the study done by Elisa Fazzi, et al., found a large prevalence of ocular motility disorders accounting for $57.3 \%$ of the eyes [7]. Ptosis was found in 1 child (2\%) in our study In our study agrees with that reported in other studies $(1.43 \%, 1.02 \%, 2.5 \%)[8-10] .74 \%$ of eyes had a

Shaikh R | Volume 1; Issue 1 (2020) | JOAR-1(1)-005 | Research Article

Citation: Shaikh R. A Study on Ocular Manifestations Seen in Patients with Cerebral Palsy. J

Ophthalmol Adv Res. 2020;1(1):1-7. 
normal fundus. Optic atrophy (20\%) and optic nerve head hypoplasia (6\%) was found in our study. Taylan, et al., in his study reported disc pathologies such as paleness (18.3\%), cupping (10.3\%), hypoplasia (4.9\%) and optic atrophy (5.7\%) which is in accordance with our study [11]. The prevalence of optic atrophy was higher when compared to other studies. Our study had certain limits like difficulty in performing tests on children with $\mathrm{CP}$ and assessment of accurate visual acuity owing to patient factors and non-availability of VEP [12].

\section{Conclusions}

In this study we found that children with cerebral palsy are at a greater risk of developing abnormalities of the eye. Hence, they should undergo a detailed ophthalmic examination at regular intervals of time. An awareness regarding these manifestations and their correction among the treating physicians for prompt referral to an ophthalmologist for detailed ocular evaluation needs to be done. The parents need to be informed about the importance of regular eye check-ups as it is crucial to limit the morbidity of the patient and also aids in overall development. Early diagnosis and intervention can prevent untoward complications and improve quality of life of the patient. A complete ocular evaluation of children with cerebral palsy is a tedious task. Appropriate management of the underlying disorder like correction of any refractive error, any corrective surgery if required and rehabilitation may help decrease the morbidity in children with cerebral palsy.

\section{References}

1. Ghai OP. Essential Paediatrics. 2007;5(1):1-2.

2. Katoch S, Devi A, Kulkarni P. Ocular defects in cerebral palsy. Ind J Ophthalmol. 2007;55(2):154.

3. Bodunde OT, Ademola-Popoopla DS, Ojuawo A, Adeboye MA. Ocular findings in children with cerebral palsy attending a tertiary hospital in north central Nigeria. Sierra Leone J Biomed Res. 2015;7(2):1-7.

4. Govind A, Lamba PA. Visual disorders in cerebral palsy. Ind J Ophthalmol. 1988;36:88-91.

5. Marasini S. Ocular manifestation in children with cerebral palsy. Optom Vis Dev. 2011;42(3):178-182.

6. Govind A, Lamba P. Visual disorders in Cerebral Palsy. Ind Ophthalmol. 1988;36:88-91.

7. Fazzi E, Signorini SG, La Piana R, Bertone C, Misefari W, Galli J, et al. Neuro-ophthalmological disorders in cerebral palsy: ophthalmological, oculomotor, and visual aspects. Develop Med Child Neurol. 2012;54(8):730-6.

8. Ozturk AT, Berk AT, Yaman A. Ocular disorders in children with spastic subtype of cerebral palsy. Int J Ophthalmol. 2013;6:204-10.

9. Park MJ, Yoo YJ, Chung CY, Hwang JM. Ocular findings in patients with spastic type cerebral palsy. BMC Ophthalmol. 2016;16:195.

10. Scheiman MM. Optometric findings in children with cerebral palsy. Am J Optom Physiol Opt. 1984;61:3213.

11. Erkkila H, Lindberg L, Kallio AK. Strabismus in children with cerebral palsy. Acta Ophthalmol Scand. 1996;74:636-8.

12. Pigassou-Albouy R, Fleming A. Amblyopia and strabismus in patients with cerebral palsy. Ann Ophthalmol. $1975 ; 7: 382-7$. 
Shaikh R | Volume 1; Issue 1 (2020) | JOAR-1(1)-005 | Research Article

Citation: Shaikh R. A Study on Ocular Manifestations Seen in Patients with Cerebral Palsy. J Ophthalmol Adv Res. 2020;1(1):1-7. 